\title{
Research on Validity Analysis of Careful Reading in CET 4 Hanhan CHENG
}

City College, Wuhan University of Science and Technology, Wuhan, 430083, China

E-mail: 16340470@qq.com

\author{
Key words: CET 4; Reading Comprehension; Language Test; Validity
}

\begin{abstract}
CET 4, a national English teaching test hosted by Department of Higher Education, Ministry of Education, is now a large-scale nationwide criterion-referenced test for non-English majors. Reading comprehension, as a typical type in English test, its validity has captured most people's attention. Thus, this paper takes six test papers from December, 2013 to June, 2014 as samples and studies the validity of students' careful passage reading based on theories about syllabus request and language test. The results turn out that the setting of careful reading is successful while studies on the genre, theme, structure, length and reading skills test are urgently to be improved.
\end{abstract}

\section{Introduction}

\section{A. Definition of CET 4}

College English Test Band (CET 4) is a nationwide teaching test hosted by Department of Higher Education, Ministry of Education. [1] It focuses on the implementing college English teaching syllabus, providing objective accurate test of college students' English proficiency and finally improving the teaching quality of college English. Thus, how to further improve CET 4 and to make it better serve teaching is undoubtedly become the hot spot of foreign language test and teaching.

\section{B. Definition of Reading Comprehension}

For a long time, reading comprehension not only captures English teachers' most attention, but also becomes an important part of college English tests. [2] According to College English Curriculum Requirements, college English aims to improve students' comprehensive competence to use college English and different English ranks mean different mastery degree of English. After the reform in December, 2013, reading comprehension includes three parts, i.e. cloze, passage match and multiple choices. Since multiple choices are the most stable traditional test type with the highest marks, it is worth more studies. [3] Therefore, to check whether it complies with the Examination Syllabus and whether it has positive effect on English teaching, this paper analyzes the validity of reading text of multiple choices.

\section{Definition of Validity}

Validity of language test reflects dependency, namely the correlation between test and test objectives. According to structuralism testers, validity of language test aims to check whether it can test what it is intended to test. And only the answer is yes, it is valid (Heaton, 1989).

\section{Validity Analysis of Careful Reading}

\section{A. Methodology}

This paper takes the reading texts of six test papers from December, 2013 to June, 2014 as samples. In accordance with the Curriculum Requirements and Examination Syllabus, we try to analyze the content validity of reading comprehension from perspectives of genre, theme, reading speed and questions. We hope to find out the current situation and trends of question setting and accordingly provide some corresponding suggestions for question setting and college English teaching. The author tables the results among the three factors, which are genre and theme, reading speed and testing skills and accordingly conduct analysis on the data summary. This study combines 
quantitative and qualitative analysis. Firstly, the author tables the collected data and summarizes them. Then, he contrasts the data with the required data in Curriculum Requirement. After that, he analyzes the content validity of reading comprehension in CET 4 and draws conclusion.

\section{B. Analysis and Contrast}

\section{a. Genre and Theme}

The appropriateness of reading content largely depends on its genre and theme in that different genres always mean different reading methods and content. [4] Hence, it is necessary to elaborate on genre of reading texts to get preliminary validity analysis. According to the Examination Syllabus, the reading texts should cover various genres and reach the middle level of language difficulty. That means, they should include argumentation, narration, and exposition and so on as well as cover society, culture, common knowledge and scientific knowledge.

Table 1 and Table 2 show that the genre and theme of CET 4 reading texts basically meet the requirements of the Examination Syllabus -- covering social, scientific, educational and economic knowledge and including narration and exposition. Besides, all reading texts are academic passages instead of novels or poems. However, if conducting further analysis on each examination paper, the author holds that the validity of some reading texts need further study.

On one hand, genre types of these reading texts are limited. It is common that all selected texts are argumentation and exposition, especially argumentation, both always mixing with some narration. However, the absence of pure narration reflects the genre simplification and thoughtlessness. Some students will summarize the rule of question setting and choose to avoid practicing texts of other genres. It not only goes against the Curriculum Requirements, but also has bad effect on students' reading practice. Though this problem is not common in CET 4, it should be reduced so as to avoid objective factors not good to students and ensure the quality of such large-scale criterion-referenced test. On the other hand, the newly two examination papers give special focus to certain discipline or circle, which to some degree results in the lack of comprehensiveness in themes. For instance, the reading texts of the paper I, paper II in December, 2013, and the paper I in June, 2014 focus on the theme of social life. It goes against the Examination Syllabus and may even have bad effect on students who participate in both examinations. But back to our study objects -- reading comprehension, we haven't taken cloze and passage match in to consideration. Thus, this assumption needs further study.

Table 1: Genres of careful reading in CET 4 from Dec., 2013 to Jun. 2014

\begin{tabular}{|c|c|c|c|c|}
\hline${ }_{\text {Year }}$ Genre & Argumentation & Narration & Exposition & Practical writing \\
\hline Paper I, Dec., 2013 & 1 & & 1 & \\
\hline Paper II, Dec., 2013 & 1 & & 1 & \\
\hline Paper III, Dec., 2013 & 2 & & & \\
\hline Paper I, Jun., 2014 & 1 & & 1 & \\
\hline Paper II, Jun., 2014 & 2 & & & \\
\hline Paper III, Jun., 2014 & 2 & & & \\
\hline Total & 9 & & 3 & \\
\hline
\end{tabular}


Table 2: Themes of careful reading in CET 4 from Dec., 2013 to Jun. 2014

\begin{tabular}{|c|c|c|c|c|c|c|}
\hline $\begin{array}{l}\text { Year } \\
\text { Theme }\end{array}$ & Social life & Science & Medicine & Economy & Ire and edu & Others \\
\hline Paper I, Dec., 2013 & 2 & & & & & \\
\hline Paper II, Dec., 2013 & 2 & & & & & \\
\hline Paper III, Dec., 2013 & & & & 1 & 1 & \\
\hline Paper I, Jun., 2014 & 2 & & & & & \\
\hline Paper II, Jun., 2014 & 1 & & & & 1 & \\
\hline Paper III, Jun., 2014 & 1 & & 1 & & & \\
\hline Total & 8 & & 1 & 1 & 2 & \\
\hline
\end{tabular}

\section{b. Reading Speed}

In the newly-reformed CET 4, the reading comprehension includes three parts -- cloze, passages match and careful reading (or multiple choices). And students are supposed to finish them in 40 minutes. According to their marks distribution and characteristics, we usually think that the reasonable time for careful reading is 20 minutes. Hence, the default time over our study on reading speed is 20 minutes.

According to the Examination Syllabus, fast reading materials always consist of 1000 words by adopting one or two long article or several short texts. And students are supposed to finish them by means of skimming and scanning in 15 minutes. That means, they should read 100 words per minute. For the part of careful reading, students are required to complete multiple choice of two passages with 300-350 words and cloze or short answers of the third text respectively with 200-250 words or 300-350 word. So the total number of words in careful reading is $800-1050$ and the supposed time is 25 minutes. Thus, the reading speed of careful reading is 32-42 words per minutes.

Table 3: Reading speed of careful reading in CET 4 from Dec., 2013 to Jun. 2014 Year

\begin{tabular}{|l|c|c|c|c|} 
& $\begin{array}{c}\text { Number of words } \\
\text { in reading texts }\end{array}$ & $\begin{array}{c}\text { Number of words } \\
\text { in question stems }\end{array}$ & Reading time(min.) & $\begin{array}{l}\text { Reading speed } \\
\text { (words/min.) }\end{array}$ \\
\hline Paper I, Dec., 2013 & 724 & 475 & 20 & 69 \\
\hline Paper II, Dec., 2013 & 721 & 499 & 20 & 57 \\
\hline Paper III, Dec., 2013 & 712 & 422 & 20 & 63 \\
\hline Paper I, Jun., 2014 & 771 & 497 & 20 & 54 \\
\hline Paper II, Jun., 2014 & 706 & 381 & 20 & 54 \\
\hline Paper III, Jun., 2014 & 692 & 382 & & 53 \\
\hline
\end{tabular}

According to the Examination Syllabus, the average number in each text is 360 and the average reading speed is 36 words per minute. If counting the question stems in, the average reading speed is 58 words per minute. Through Table 3 as follows, we find out that the total number of words and reading speed in careful reading are completely consistent with these requirements. However, if we take the question stems into consideration, we surprisingly find that these speeds are far higher than the requirements. That's may be one of the reasons why some students complain about the tight time in reading.

\section{c. Question Design and Testing Skills}

Reading comprehension aims to test students' reading ability. Li Xiaoju holds that reading comprehension should test students' ability to understand from various levels and categories. The Examination Syllabus clearly indicates the goals of reading comprehension: 1) grasping the main 
idea; 2) clear about the facts and specific information supporting the main idea; 3) understanding literal meaning and proposing reasonable implication; 4) having a good grasp of single word, contextual logic relation and the profound meaning. And during the reading process, these goals are realized by specific reading skills as follows: 1) grasping the main idea; 2) locating and understanding specific information; 3) implying and summarizing the hidden meaning reasonably; 4) clear about the contextual logic relation and profound meaning generally; 5) guessing the meaning of difficult words and familiar words; 6) understanding difficult long sentences; 7) judging the author's attitude.

Table 4: Testing skills of careful reading in CET 4 from Dec., 2013 to Jun. 2014

\begin{tabular}{|c|c|c|c|c|c|}
\hline Year Testing skills & The main idea & $\begin{array}{l}\text { Location and understanding } \\
\text { of specific information }\end{array}$ & $\begin{array}{l}\text { Implication and } \\
\text { summary }\end{array}$ & $\begin{array}{l}\text { Meaning of words } \\
\text { and sentences }\end{array}$ & $\begin{array}{l}\text { Attitudes of } \\
\text { the author }\end{array}$ \\
\hline Paper I, Dec., 2013 & 1 & 7 & 1 & 1 & \\
\hline Paper II, Dec., 2013 & 1 & 8 & & & 1 \\
\hline Paper III, Dec., 2013 & & 5 & 4 & & 1 \\
\hline Paper I, Jun., 2014 & & 7 & 1 & 2 & \\
\hline Paper II, Jun., 2014 & & 6 & 3 & 1 & \\
\hline Paper III, Jun., 2014 & & 6 & 3 & 1 & \\
\hline Total & 2 & 39 & 12 & 5 & 2 \\
\hline
\end{tabular}

It is obvious that the first, fourth and seventh one are on textual level, the second, third and sixth on are on the level of paragraph and sentence and the fifth on is on lexical level. We conduct analysis on the 60 multiple choice questions of 12 texts and conclude them into five skills as shown in Table 4. According to Table 4, we find out that those questions of reading comprehensively test the required skills in the Examination Syllabus. In details, the skill to locate and understand specific information is the major skill and questions for that constitute $65 \%$ of all questions. The following skill is to imply some hidden meaning through the main idea, whose questions amount to $20 \%$ of all questions. Besides, the skills to grasp textual meaning, judge the author's attitude and guess the meaning of words are also tested. However, we also find that the three papers in 2014 give focus to the skills of analyzing specific information while ignoring the skill of understanding on textual level.

\section{Conclusions and Suggestions}

Above all, we can conclude that the reading texts in CET 4 are generally in accordance with the Examination Syllabus. They adhere to the principles of multiple genres, diverse themes, controlled reading speed and comprehensive testing points that check students' reading skills and strategies. [5] However, there are also some problems like how to keep balance between genre and theme and how to avoid different levels of difficulty among different papers and different passages. To improve the quality of reading comprehension in CET 4, the author gives some corresponding suggestions: 1) the selected texts should treat all genres equally instead of preferring to argumentation and exposition; 2) the selected texts should cover kinds of themes instead of focusing on humanity, society, education and economy; 3) the reading speed should take the question stems into consideration; 4) questions should not only check students' location and understanding of specific information, but also their discourse comprehension. Generally speaking, the question design of reading comprehension in CET 4 by far is acceptable and thoughtful. But we still hope that question designers can make full use of the studies on validity analysis of reading comprehension and then constantly improve their question design and even the quality of CET 4. 


\section{References}

[1] Resnik,P.WordNet and class-based probabilities. WordNet: An Electronic Lexical Database . 1998

[2] Schumann,J.Second Language Acquisition: the Pidginization Hypothesis. Second Language Acquisition: A Book of Readings . 1978

[3] Shermis, M,Barrera, F.Exit assessments: evaluating writing ability through automated essay scoring. . 2002

[4] Jan Nuyts,Pieter Byloo,Janneke Diepeveen. On deontic modality, directivity, and mood: The case of Dutch mogen and moeten [J]. Journal of Pragmatics. 2009 (1)

[5] Yuh-Huey Lin. Query preparatory modals: Cross-linguistic and cross-situational variations in request modification [J]. Journal of Pragmatics. 2008 (8) 